\title{
ASSESSMENT OF THE USE OF PRELIMINARY CONCEPTS TEST AND RUBRICS IN PRACTICAL LEARNING AT UNIVERSITY
}

\author{
I. Llop-Harillo, A. Pérez-González, F. Sánchez-Marín \\ Department of Mechanical Engineering and Construction, Universitat Jaume I (SPAIN)
}

\begin{abstract}
The high number of students and teachers in the laboratory practices of the course Theory of Machines and Mechanisms, shared by several engineering degrees at Universitat Jaume I, makes the teaching planning and evaluation challenging. Some issues were observed in past years, such as differences in the student knowledge of basic concepts, underpreparation before practical classes, poor quality of the written reports, absence of common objective assessment criteria among teachers and low success rate. That led us to the implementation of an action for educational improvement during the academic year 2018-2019. The aim was to improve the students' level of training before attending laboratory practices, to standardize the evaluation among teachers and to involve students in the process of assessment in order to improve learning outcomes and the quality of the reports delivered. The improvement action included, on one side, carrying out an initial evaluation with a diagnostic test. The results of this test were used to estimate the basic knowledge of the students and proposing specific tutorial sessions in order to unify their level of knowledge. This method should increase the students involvement and improve the success while performing the laboratory practices. On the other side, rubrics were created in order to standardize the correction criteria. These rubrics were also made public to the students, before the classes, in an attempt to improve the quality of their reports. In addition, for some of the reports the students were asked to self-assess their own reports following the public rubric. The results indicate that teachers found the rubrics useful for objective and fair evaluation. However, the standard deviation across teachers has not been apparently reduced with respect to the previous year by the use of them, although the differences in the student cohort have to be taken into account. The effect on grades of the factors teacher and session, as well as their interaction, was significant $(p<.05)$ according to the ANOVA tests, as already was prior to the application of the action. It was also found that the student grades in the practical classes did not improved significantly. A low implication in the preparation before classes and a low tutorial attendance were observed in the collective of students, possible explaining in part the discrete improvements obtained. The self-assessment improved the grades on average where it was applied. We concluded that the involvement of both students and teachers is necessary to promote learning quality using these techniques.
\end{abstract}

Keywords: Assessment, higher education, preliminary concepts, rubrics, self-assessment.

\section{INTRODUCTION}

\subsection{The course}

The course on which this study focuses is Theory of Machines and Mechanisms of the Universitat Jaume I (UJI). The subject deals with the composition of machines and their mechanisms. It covers the study of techniques and procedures to analyse, from the point of view of statics, kinematics and dynamics, the elements composing the machines and the machine overall.

The students are organized in four theory groups with four different teachers and fifteen laboratory practice groups distributed among five teachers. This quantity of groups is because the students come from three different bachelor's degrees: Mechanical Engineering, Electrical Engineering and Industrial Technology Engineering, being 267 the total number of students who have studied the subject in the academic year 2018/2019. It is important to highlight that each group, for both theory and laboratory, is composed by a mix of students coming from the three degrees. In all degrees, this subject is mandatory and taught in the second term of the second year.

The subject includes five practical sessions per laboratory practice group. Their evaluation is part of the continuous evaluation of the subject. Two sessions are taught in the mechanical engineering laboratory classroom (workshop). One of these sessions deals with the mobility of mechanisms and the analysis of their mechanical advantage and the other one focus on the study of the gear trains. 
The assessment of each of these two sessions is made through a laboratory report (technical report) submitted by small subgroups of up to four students. The other three sessions are taught in a computer classroom using the Working Model 2D (WM2D) program. The objective of these sessions is the kinematic and dynamic modelling and analysis of mechanisms. These three sessions are worked individually and evaluated through the submission of the files developed during the session.

The student is instructed to read and prepare the available session guide before attending the practical sessions. The study of the necessary theory and the proficiency in the use of WM2D, already used in a previous course, are fundamental for a correct academic achievement during these practical sessions. All the required material for the student preparation before the session is available in the virtual classroom (moodle-based) of the course: theory, practical exercises, video and written material for the resolution of exercises in WM2D, laboratory memories, document for the correct writing of a technical report, etc.

\subsection{The problem}

One of the main problems in the course is the large number of students enrolled and consequently the large number of teachers, which poses additional difficulties for teaching organization and evaluation. Several problems were detected in the teaching-learning process in previous years:

- Differences in student background.

- Lack of students' training before attending the laboratory sessions.

- Lack of tutorial attendance.

- Poor quality of the reports delivered.

- No common objective criteria established to evaluate laboratory sessions and therefore variability among teachers in the assessment criteria.

- Low success rate in the subject and high dropout rate.

\subsection{Related work}

The literature is plenty of innovative teaching methods allowing a dynamic learning and different strategies for the evaluation of transversal skills, with useful ideas applicable to this course to improve the identified problems.

De Miguel [1] analysed different teaching modalities and teaching methods, and proposed, for each of these methods, the most appropriate systems to evaluate the corresponding learning. Biggs et al. [2] explained how students learn and described innovative methodologies for teaching effectively. Marqués [3] analysed the flipped classroom methodology and argued about why it fosters learning, establishing some guidelines for its implementation.

Brown et al. [4] showed how assessment methods can be part of the learning process, highlighting the self-assessment and the group assessment as tools to foster quality learning. Padilla et al. [5] also noted the importance of learning-oriented assessment as a method to optimize the learning process, stating that assessment tasks must also be learning tasks. They also showed the importance of feedback to guide future work, and the need to involve students in the process of evaluating their own work. Fernández [6] highlighted the assessment in competency-based training with evaluative strategies such as the quality feedback and the self-assessment or peer assessment. In addition, she analysed the role of rubrics to achieve a quality assessment that is useful for both students and teachers, explaining also the appropriate guidelines to follow for its design. Brown [7] deepened into the advantage that authentic assessment offers to students, through practical implementations, rubrics and reflection, among others.

\subsection{Aim}

The objectives proposed in this action of educational improvement were:

- Improving the students' training before attending the laboratory sessions.

- Standardizing the evaluation among teachers.

- Involving students in the process of evaluating their own work in order to optimise learning and to improve the quality of the reports delivered. 


\section{METHODOLOGY}

In order to meet the proposed objectives, two different procedures have been followed. On the one hand, active methodologies have been used through undertaking diagnostic tests about preliminary concepts of WM2D before attending the corresponding practical sessions. In addition, specific tutorials have been established according to the results obtained in these tests on preliminary concepts. On the other hand, some rubrics have been prepared and these were shared among teachers and made visible to the students. For the two workshop sessions evaluated with a technical report, a selfevaluation was added at the end of the report using the corresponding rubrics. Finally, a questionnaire has been created for the laboratory teachers to analyze the performance and their opinion regarding the methodologies used.

In order to evaluate the success of the educational improvement, three aspects have been analyzed:

1 Comparison of the mean grades of the computer classroom practices with respect to those of the previous year, in order to analyze the effect of the preliminary concepts test and the specific tutorials.

2 Comparison of the mean grades of the workshop practices with respect to those of the previous year, to analyze the effect of the newly introduced self-evaluation.

3 Difference in the scattering of grades among teachers, to analyze the effect of the use of rubrics for the assessment.

\subsection{Preliminary concepts test}

A test of previous WM2D concepts was created at the virtual classroom, in order to enhance students' training with the program used in the three computer classroom practices. Familiarization of the students with the software was done in a previous course and additionally they had resources at the virtual classroom of the course such as guides and videos with practical exercises of WM2D. All the students had the test available for one week prior to the earlier group first session. They had only one response attempt for the test and it was part of an initial diagnostic evaluation. Although the grade obtained in the test did not accounted for the final grade, a non-delivery of the test resulted in a $20 \%$ penalty in the grade for the three computer classroom practices. For the type of questionnaire and the questions it consisted of, it has been taken into account that it is an initial diagnostic evaluation. Taking into account the Bloom's taxonomy [8] and considering that the test is a diagnostic evaluation, the questions were focused on finding out whether students remembered information learned in previous related courses and whether they understood the basic concepts about using the program to solve practical exercises. The students with a grade in the test lower than 5 points out of 10 , were recommended to attend a tutorial before starting the practical sessions in the computer classroom. Some laboratory teachers organized a group tutorial in the computer classroom, focused on solving doubts about WM2D while using the software.

\subsection{Rubrics}

One specific rubric was developed for each one of the five practical sessions. These rubrics are divided into several sections, evaluating different knowledge and skills. In addition, each section has associated an assessment criterion with a scoring scale. The five rubrics have been published in the virtual classroom of the course, being available by the students before the date of the corresponding session. Like this, they knew how they were going to be evaluated before attending the sessions and performing the respective task. In addition, the students must self-evaluate their reports with the rubrics for the two workshop sessions, promoting reflection on the task performed. It should be noted that the students receive graded feedback on each section of every rubric rather than only a single global grade.

\section{RESULTS}

Fig. 1, obtained from the questionnaire passed to laboratory teachers, indicates that only one of the five teachers organized a group tutorial to clarify WM2D queries. This teacher informed that this tutorial was attended by about $20 \%$ of their students. However, the information obtained from the same questionnaire indicates that $40 \%$ of the laboratory teachers noted a reduction in the disparity of the students background at the computer classroom sessions, attributed to the effect of the preliminary concepts test and the specific tutorials suggested. The questionnaire also indicated an 
approximate improvement of $10 \%$ with respect to the previous year in the percentage of students who apparently prepared the practices before attending the laboratory sessions, reaching an approximate percentage of $30 \%$ during this academic year. On the other hand, with regard to the rubrics, $100 \%$ of the teachers considered them useful, $80 \%$ considered that they make the assessment more objective, $80 \%$ considered them helpful to the students to improve the quality of their work and $100 \%$ considered that the rubrics make the assessment between teachers fairer and more equitable. Regarding the selfevaluation with the rubric in the reports of the workshop sessions, $40 \%$ of the teachers considered that the students have objectively evaluated themselves, and $60 \%$ considered that some of their groups have done it objectively but not all of them.

\section{Have you organized a specific Working Model tutorial after obtaining the results of the preliminary concepts test?}

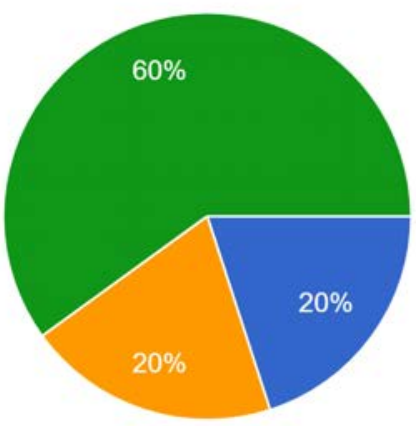

Yes, I've organized a group tutorial in the computer classroom

Yes, I've proposed a specific tutorial in my office

No, but some students came to my regular tutorials

No and no students came to tutorials before the computer classroom sessions

Figure 1. Percentage of teachers who established specific tutorials depending on the result obtained in the preliminary concepts test.

Fig. 2 shows the mean and standard deviation (SD) of the students' grades across all the sessions from each of the five laboratory teachers in the present academic year 2018/2019 and in the previous one (2017/18). In both cases, the deviations overlap, suggesting that there are no significant differences. However, in a univariate analysis with SPSS Statistics program, with the grades as dependent variable and the teacher and session as fixed factors, significance was obtained for both factors and for their interaction $(p<0.05)$ in both academic years. Fig. 3 shows the effect of both factors for each academic year. It should be noted that teachers 1 to 4 are the same in both academic years, but teacher 5 is not the same in the academic year 2017/2018 and 2018/2019.

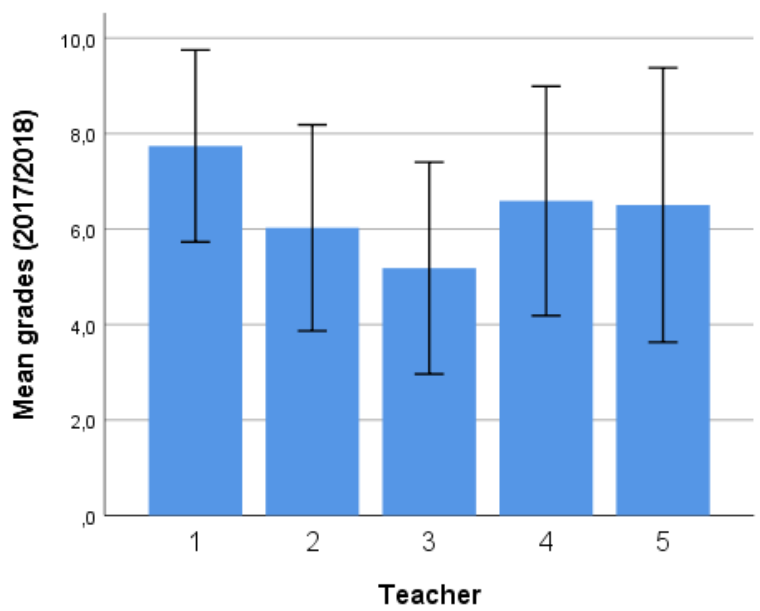

Error bars: +/- 1 SD

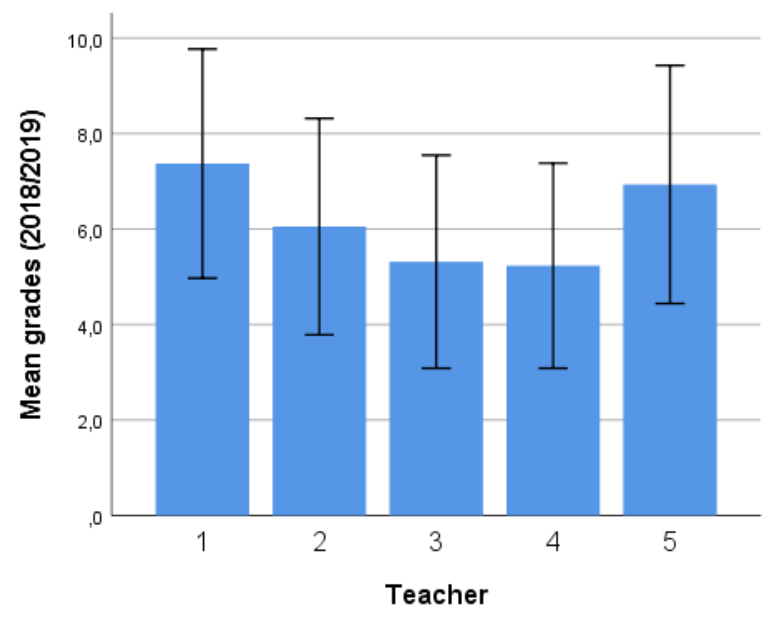

Error bars: +/- 1 SD

Figure 2. Mean and standard deviation (SD) of all grades per teacher. Left: academic year 2017/2018; right: academic year 2018/2019 in which the educational improvement has been implemented. 

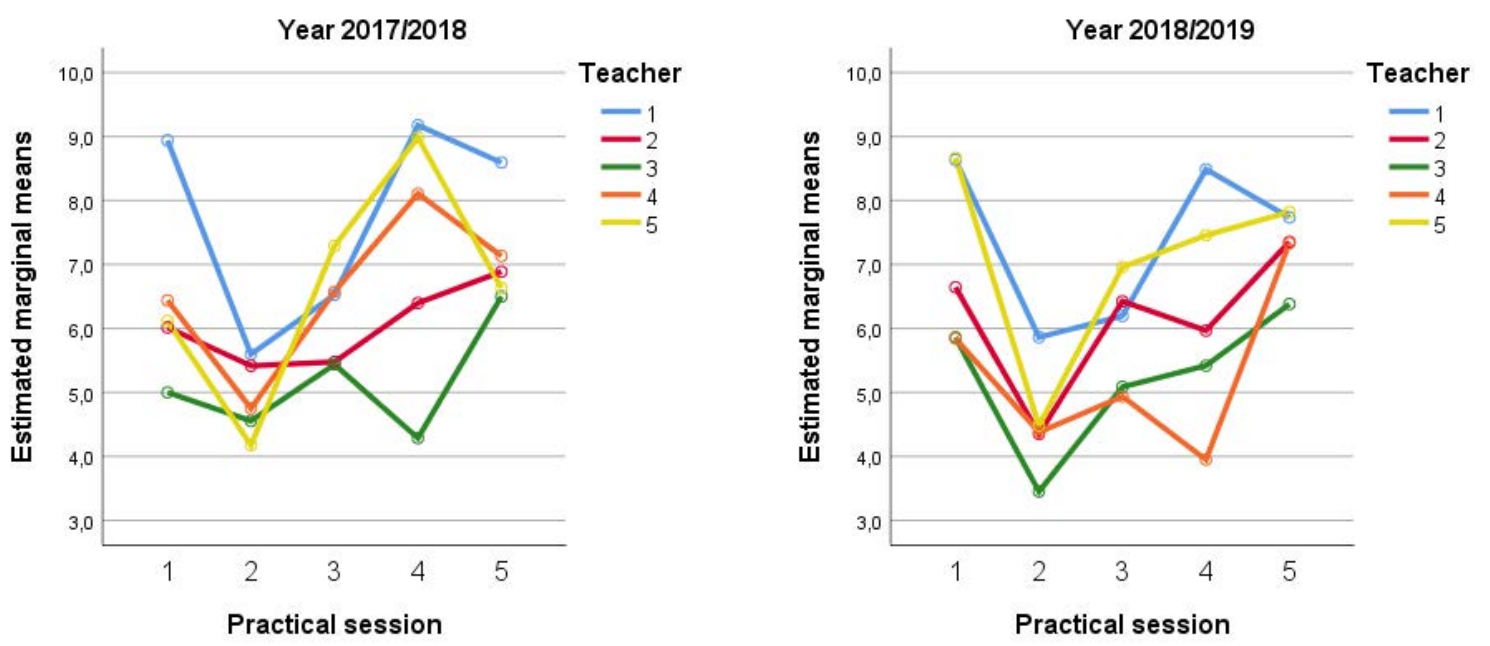

Figure 3. Effect of the factors teacher and practical session in the mean grades. Left: academic year 2017/2018; right: academic year 2018/2019.

Fig. 3 gives a graphical insight of the SD of the mean grades awarded by the five teachers for each of the five laboratory sessions of the subject. Assuming a random distribution of students among groups, a normal distribution of grades in each group would be expected, with the same mean in all of them. With the introduction of rubrics in 2018/19 we expected this SD among teachers to be small to indicate that the evaluation method is objective. On average, the SD among teachers is about 1.0 point (out of 10) for both academic years, a value that is considered reasonable. It should be noted that this deviation has not been calculated by assessing the same work by several teachers, but each teacher assessed the students in their laboratory groups, among which there is also a difference in the mean grade of the academic record. For the academic year 2018/2019, the SD of the academic record's mean grade between the groups corresponding to each teacher is 0.3 points, with teacher 1 having students with the highest average (6.6/10) and teacher 4 having the lowest (5.9/10). As can be seen in Fig. 2 (right), this difference in the mean grades in the academic record is in agreement with the mean grade obtained in these laboratory sessions.

Table 1 shows that the differences in the mean grades between the two years in general are small, improving the mean grade of the workshop sessions in the academic year 2018/2019 and worsening those of the WM2D sessions. The improvement in the average qualification of the workshop sessions with the introduction of the rubrics and the self-evaluation by the students through these could be greater. However, it is worth highlighting, that this improvement is limited by some penalizations applied in the rubrics for these laboratory practices of up to -4 points out of 10 , penalizations that were not applied the previous year. On the other hand, for the first WM2D session, which should have been most influenced by the preliminary concepts test and the specific tutorials, the difference in the mean grade is smaller. It is worth noting that the mean grade of the preliminary concepts test was 4.7 , which highlights a low previous knowledge of the software by the students. In addition, the SD between the test grades was 2.7 points, revealing the difference in previous knowledge among students. As it has been shown in Fig. 1, the students after knowing their low-grade on the test and therefore their low knowledge of the WM2D program have not shown interest in acquiring that knowledge before doing the first computer classroom session, despite the fact that everyone was advised to attend tutorials especially if their grade was less than 5 out of 10 . With the progress of the computer classroom sessions and therefore greater practice with WM2D, an improvement in the grades is observed in Table 1. It should also be highlighted that this difference in the mean grades between the two academic years is affected by the penalizations applied this last year with the use of rubrics. These penalizations have affected several students with a grade penalization of up to -8 points out of 10 , which justifies a lower average in the academic year 2018/2019. 
Table 1. Mean (SD) grades in each academic year differentiating the sessions performed in the workshop (W) and in the computer classroom with Working Model 2D (WM2D).

\begin{tabular}{l|c|c}
\hline \hline \multicolumn{1}{c|}{ Session } & $2017 / 2018$ & $2018 / 2019$ \\
\hline $1(\mathrm{~W})$ & $6,9(2,0)$ & $7,2(2,0)$ \\
\hline $2(\mathrm{WM} 2 \mathrm{D})$ & $5,0(2,5)$ & $4,7(2,4)$ \\
\hline $3(\mathrm{WM} 2 \mathrm{D})$ & $6,4(2,4)$ & $5,9(2,3)$ \\
\hline $4(\mathrm{WM} 2 \mathrm{D})$ & $8,0(2,3)$ & $6,3(2,8)$ \\
\hline $5(\mathrm{~W})$ & $7,3(1,6)$ & $7,5(1,6)$ \\
\hline Total & $6,7(2,4)$ & $6,3(2,5)$ \\
\hline \hline
\end{tabular}

\section{CONCLUSIONS}

With this study it can be concluded that in order to make the techniques used (preliminary concepts test, specific tutorials to standardize previous knowledge, rubrics and self-evaluation by the students) to promote quality learning to be effective, it is necessary to involve both teachers and students. The preliminary concepts test as an active methodology has resulted in an involvement by students to remember concepts learned in previous subjects. On the other hand, the rubrics have mainly allowed the uniformity of the assessment criteria among the different laboratory teachers and a better understanding of these criteria by the students, thereby fostering reflection and control over the learning process through the self-assessment.

\section{ACKNOWLEDGEMENTS}

We acknowledge the other teachers of the course, Francisco Javier Andrés de la Esperanza, María José Serrano Bellés, José Luis Iserte Vilar, José Feliciano Fuentes Ballesteros, José Vilarroig Herrera and Victor Roda Casanova, for their involvement in carrying out this educational improvement.

We also acknowledge Esther Climent Tormos, who is in charge of the beginner teacher training programme, and Miguel Ruiz Garrido, co-director of the Seminari Permanent d'Innovació Educativa de Docència en Anglès (SPIEDA), for their support to complete this educational improvement.

\section{REFERENCES}

[1] M. De Miguel Díaz, Modalidades de enseñanza centradas en el desarrollo de competencias. Spain: Universidad de Oviedo, 2005.

[2] J. Biggs and C. Tang, Teaching for Quality Learning at University. Society for Research into Higher Education \& Open University Press, 2007.

[3] M. Marqués, "Qué hay detrás de la clase al revés (flipped classroom)", ReVisión, vol. 9, no. 3, 2016.

[4] S. Brown and A. Glasner, Evaluar en la universidad: problemas y nuevos enfoques. Spain: Narcea, 2003.

[5] M. T. Padilla Carmona and J. Gil Flores, "La evaluación orientada al aprendizaje en la Educación Superior: condiciones y estrategias para su aplicación en la docencia universitaria", revista española de pedagogía, vol. 66, no. 241, pp. 467-486, 2008.

[6] A. Fernández March, "La evaluación orientada al aprendizaje en un modelo de formación por competencias en la educación universitaria", REDU. Revista de Docencia Universitaria, vol. 8, no.1, pp. 11-34, 2010.

[7] S. Brown, "Authentic assessment: using assessment to help students learn", RELIEVE, vol. 21, no. 2, 2015.

[8] B. S. Bloom, Taxonomy of Educational Objectives: The Classification of Educational Goals. McKay, 1956. 